\title{
Effect of Quasi-Isotropic Antenna Orientation on Indoor Multipath Propagation Characteristics in RSN Applications
}

\author{
Abdelhamid Bou-El-Harmel, Ali Benbassou, Jamal Belkadid, and Nadia Mechatte \\ Laboratory of Transmission and Processing Information Eq. EMC/Telecom, High School of Technology, \\ Sidi Mohamed Ben Abdullah University, Road IMOUZZER, 2427 Fez, Morocco
}

Correspondence should be addressed to Abdelhamid Bou-El-Harmel; abdelhamid.bouelharmel@usmba.ac.ma

Received 16 January 2017; Revised 2 April 2017; Accepted 2 May 2017; Published 29 May 2017

Academic Editor: María Elena de Cos Gómez

Copyright (C) 2017 Abdelhamid Bou-El-Harmel et al. This is an open access article distributed under the Creative Commons Attribution License, which permits unrestricted use, distribution, and reproduction in any medium, provided the original work is properly cited.

\begin{abstract}
In the RFID sensor networks (RSN), the orientations of the antennas used in the network nodes have a significant influence on the propagation characteristics. In this article, we investigated the effects of the two antennas' orientation of different radiation and polarization on the multipath propagation characteristics. This study is evaluated in a typical indoor environment by computer simulations based on the three-dimensional (3D) ray-tracing method. This method is based on geometric optics and uniform diffraction theory and also it offers significant advantages in terms of accurate and comprehensive prediction of propagation characterization. The simulations have been performed at frequency $915 \mathrm{MHz}$ and the propagation characteristics are compared in terms of received power level $(\mathrm{Pr})$ and Root-Mean-Square (RMS) delay spread for a quasi-isotropic 3D cubic antenna with circular polarization and for an omnidirectional dipole with linear polarization in the LOS, NLOS, and OLOS scenarios.
\end{abstract}

\section{Introduction}

The RFID sensor network (RSN) is a technology belonging to the wireless personal area network (WPAN). This new technology is the result of the integration of Radio Frequency Identification (RFID) technology [1] and Wireless Sensor Network (WSN) technology [2] because there are a number of advantages by merging these two technologies to meet the needs of certain applications [3-6].

The RSN architectures are the possible architectures to integrate RFID and WSN. According to researches [3-6], there are four types of integrations class: (1) integration of RFID tags with sensors, (2) integration of RFID tags with WSN sensor nodes, (3) integration of RFID readers with WSN sensor nodes, and (4) mixed RFID and WSN.

In the RSN, the nodes of this network communicate with each other by a radiofrequency link. The problems contributing to poor radiofrequency communication between two nodes of the RSN may have two origins:

(i) The propagation channel: this corresponds to the environment traversed by the electromagnetic waves during an information transmission between the RSN nodes. In an environment, the node receives the waves coming through different paths due to the interaction of the signal emitted with the numerous obstacles (reflection, transmission, diffraction, etc.) existing in the environment. The received signal is the sum of many echoes (multipath) of the transmitted signal arriving to the receiver node with some attenuation, some phase shift, and some delay, due to the path length. These different echoes are generated at the level of the receiver constructive or destructive interferences which can lead to a significant deterioration of the received signal.

(ii) The antennas: they are fundamental and essential elements in the wireless communication between the nodes of the RSN. Due to different antennas types, they have different radiation characteristics perfectly adapted to the application or to the environment envisaged. For example, a conventional dipole antenna does not radiate in the directions of its axis. This radiation anisotropy affects the quality of the transmission which relies on the orientation of the antennas. 
In previous works, the authors in [7] investigated the effects of the radiation patterns of the antennas at remote terminals on multipath propagation characteristics. These effects were examined by indoor propagation measurements at $60 \mathrm{GHz}$ conducted in a modern office room and by ray-tracing simulations based on geometrical optics. An omnidirectional antenna is used by the transmitter and four antenna types (omnidirectional antenna and threedirectional antennas with wide, medium, and narrow beam width) are used by the receiver in a fixed manner without orientation of the antennas. The work [8] introduces results of computer simulation based on a three-dimensional (3D) RT method for various directional polarized antennas, where the effects of antenna polarization on power and RMS delay spread are investigated in line-of-sight (LOS) and out-ofsight (OOS) indoor channel. The carrier frequency of the two antennas is $2.4 \mathrm{GHz}$. Both the transmitting and receiving antennas are typical half wavelength polarized dipoles. The two transmitting antennas are vertical polarization, while receiving antennas have both vertical polarization and horizontal polarization.

In this work, we will investigate the effects of the two antennas' orientation of different radiation and polarization on the multipath propagation characteristics. This study is evaluated in a typical indoor environment by computer simulations based on the three-dimensional (3D) ray-tracing method. The first antenna is a half-wave dipole antenna that we designed in [9] which has an omnidirectional radiation pattern in donut form with linear polarization. The second antenna is a $3 \mathrm{D}$ cubic antenna that we designed in [10] which has a quasi-isotropic radiation pattern with circular polarization. The simulations have been made at frequency $915 \mathrm{MHz}$ with a transmission power of $0 \mathrm{dBm}$ in a typical indoor environment. The propagation characteristics are compared in terms of the received power level $(\mathrm{Pr})$ and RootMean-Square (RMS) delay spread for different orientation of the two antennas in the line-of-sight (LOS), non-line-of-sight (NLOS), and obstructed-line-of-sight (OLOS) scenarios.

This paper is organized as follows. The first section is the introduction. Section 2 describes the environment, the procedure, and the simulation model used. Section 3 presents the results obtained after the simulations in each scenario. Finally, Section 4 is devoted to the conclusion and some perspectives.

\section{The Environment, Simulation Procedure, and Model}

To study the effects of orientation of each antenna on indoor propagation characteristics, we have performed the simulations in the first floor of the north wing of a research building (Figure 1) within our university.

The dimensions of the environment have a width of $25 \mathrm{~m}$, a length of $28 \mathrm{~m}$, and a height of $3 \mathrm{~m}$ as mentioned in Figures 2 and 3.

Our environment has been modeled with walls, partitions, roof, and soil which are homogeneous and having effective dielectric constants listed in Table 1 and which are obtained from a free space method using measurements of

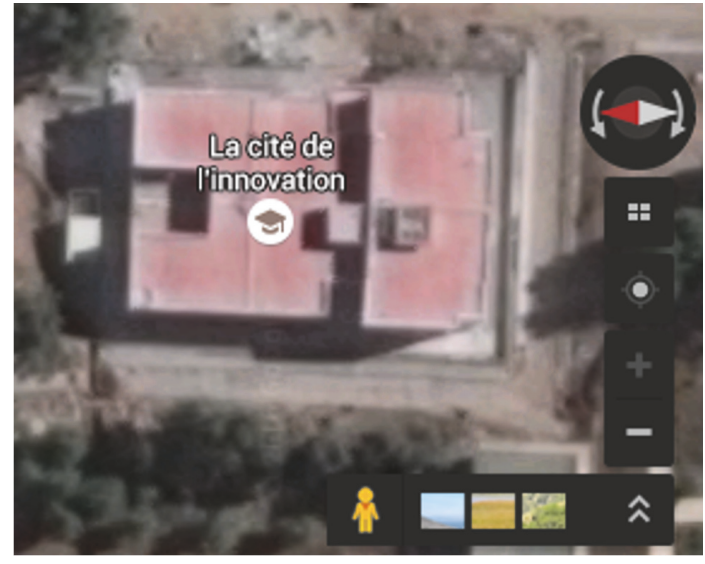

Figure 1: A view of the building taken by Google Maps.

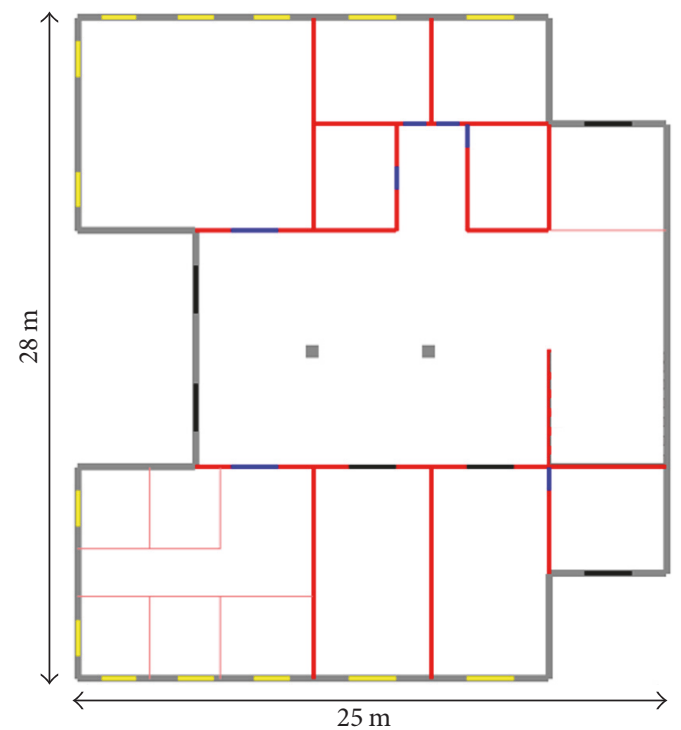

Figure 2: 2D construction plan of the first floor of the north wing of the building.

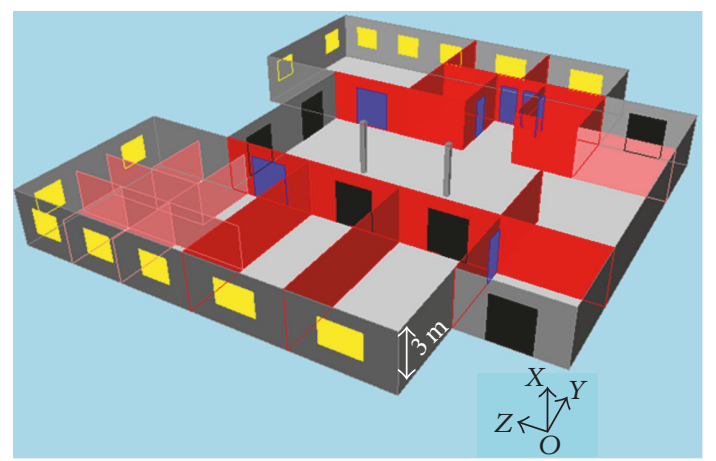

FIGURE 3: 3D construction plan of the first floor of the north wing of the building. 


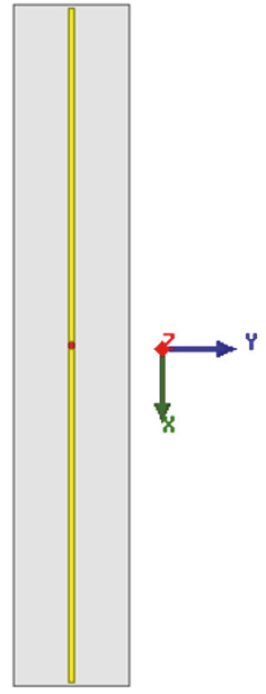

(a)

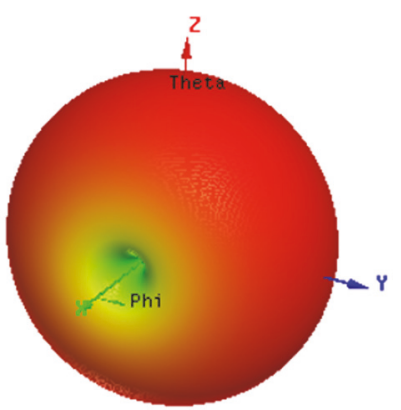

(b)

FIGURE 4: Dipole antenna: (a) form and (b) radiation pattern.

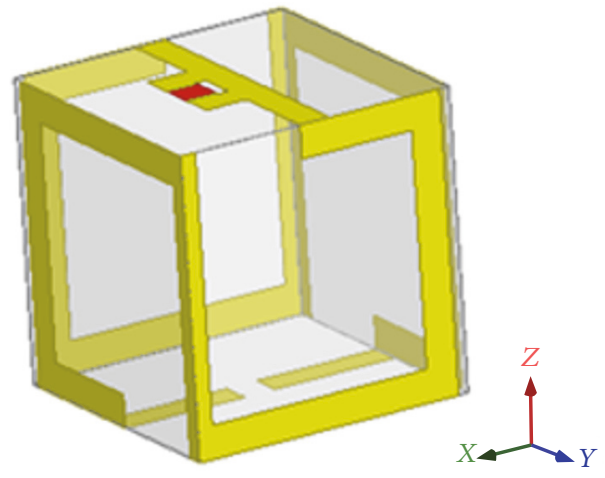

(a)

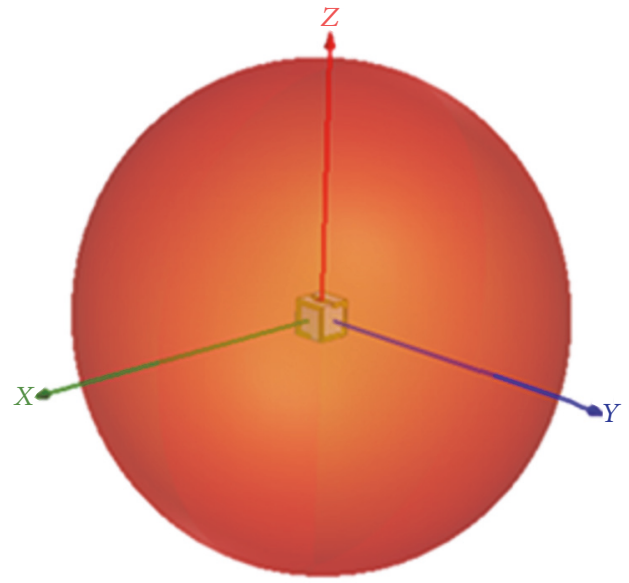

(b)

FIGURE 5: 3D cubic antenna: (a) form and (b) radiation pattern.

transmission in normal incidence [11]. In Figure 2, the gray lines represent reinforced concrete walls, the reds designate the brick walls, and the roses show the glass partitions. The black and blue bands represent the iron and wood doors, respectively, while the yellows are glass windows. The obstacles such as cupboards, desks, and machines are not modeled in this work.

In this work, we used a half-wave dipole antenna (Figure 4(a)) which produces omnidirectional radiation as donut with a maximum gain of the order of $2.14 \mathrm{dBi}$ (Figure 4(b)) [9] and a 3D cubic antenna (Figure 5(a)) which produces quasi-isotropic radiation with a maximum gain of $1.29 \mathrm{dBi}$ (Figure 5(b)) [10], as transmitting and receiving antennas for the RSN nodes.
TABLE 1: The dielectric constants of materials.

\begin{tabular}{lcc}
\hline & \multicolumn{2}{c}{$\varepsilon_{r}=\varepsilon_{r}^{\prime}+j \epsilon_{r}^{\prime \prime}$} \\
\hline Reinforced concrete wall & 6.7 & $\varepsilon_{r}^{\prime \prime}$ \\
Brick wall & 5.1 & -1.2 \\
Glass partition & 5 & -0.2 \\
Iron door & 1 & 0 \\
Wood door & 3 & 0 \\
Glass window & 5 & 0 \\
Soil & 10 & 0 \\
Roof & 10 & -1.2 \\
\hline
\end{tabular}




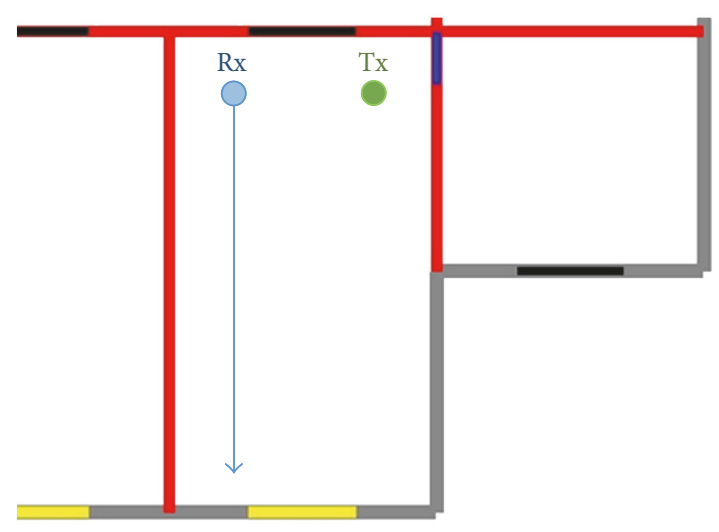

(a)

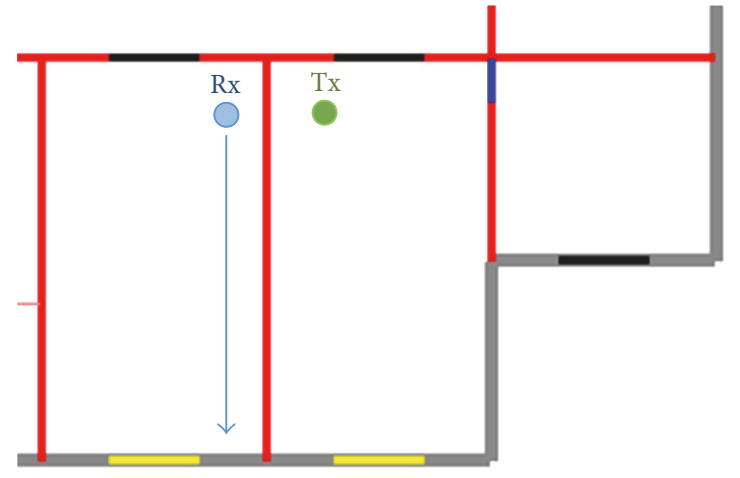

(b)

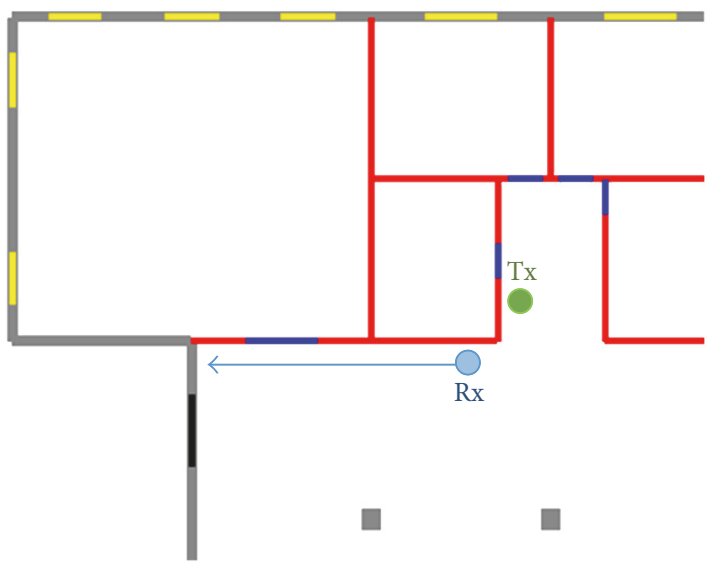

(c)

FIgURE 6: Scenarios: (a) LOS, (b) NLOS, and (c) NLOS.

Regarding the location of the transmitter and receiver, we considered three scenarios in our environment as shown in Figure 6. In scenario (a), the transmitter (Tx) and receiver $(\mathrm{Rx})$ are in the same room and there are no obstacles between them, so they are in line-of-sight (LOS). In scenario (b), the positions of Tx and Rx are changed, and the Tx and Rx are now in two different rooms, so they are in non-line-of-sight (NLOS). In scenario (c), the location of $\mathrm{Rx}$ is selected in the corridor but in the shaded area with respect to $\mathrm{Tx}$, so they are in obstructed-line-of-sight (OLOS).

In all scenarios, the frequency and transmission power used are, respectively, $915 \mathrm{MHz}$ and $0 \mathrm{dBm}$. The Tx and the $\mathrm{Rx}$ are placed with a height of $1.5 \mathrm{~m}$ above the soil and the simulations are carried out at several receiving positions by a distribution of $\mathrm{Rx}$ of a spatial pitch of $0.5 \mathrm{~m}$ along the arrow as shown in Figure 6.

We made two tests to determine the effect of antenna orientation:

(i) The first test compares the received signal power $(\mathrm{Pr})$ and the RMS delay spread in each scenario by using the dipole antenna at both $\mathrm{Tx}$ and $\mathrm{Rx}$ with the same and different orientations taking into account the polarization of the antenna. (ii) The second test compares the level of $\mathrm{Pr}$ and the RMS delay spread in each scenario by using the $3 \mathrm{D}$ cubic antenna at both $\mathrm{Tx}$ and $\mathrm{Rx}$ with the same and different orientations taking into account the polarization of the antenna.

To find the results of $P r$ level and also the RMS delay spread, we used the $3 \mathrm{D}$ ray-tracing method which is widely applied in the prediction of indoor RF propagation and which offers an accurate description of the channel taking into account multipaths. This method uses the geometric optics (GO) method [12] which describes the direct, reflected, and transmitted fields with the concept of rays. With regard to the diffraction phenomenon, this method is complemented by the Uniform Theory of Diffraction [13].

We used the radio wave propagation simulator which considers and includes the following:

(i) The precise description of our 3D environment (Figure 3) with consideration of soil and roof.

(ii) The radiation patterns of the transmitting and receiving antenna (Figures 4(b) and 5(b)).

(iii) A purely linear or circular polarization of the transmitting and receiving antenna. 


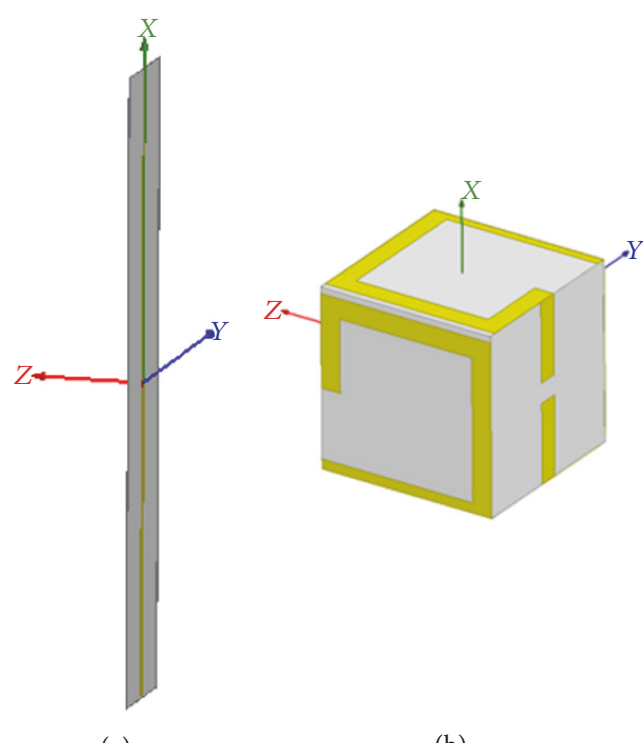

(a)

(b)

Figure 7: The Tx (0-0) orientation of the Tx antenna ( $\mathrm{Rx}(0-0)$ of the $\mathrm{RX}$ antenna): (a) dipole antenna and (b) 3D cubic antenna.

(iv) The reflections of the rays (waves) on the surfaces of the obstacles, the transmissions through the obstacles, and the diffractions on the edges and the corners of the obstacles.

(v) The maximum number of reflections, transmissions, and diffractions is of the order of five.

(vi) The inexistence of movement of people and equipment in the environment (the channel does not depend on time).

Once all propagation paths are determined, the power received in $\mathrm{dB}$ is calculated by [14]

$$
P_{r}[\mathrm{~dB}]=10 \log \left(\frac{\left|E_{\mathrm{tot}}\right|^{2}}{\eta_{0}} A\right),
$$

where (i) $\eta_{0}=\sqrt{\mu_{0} / \epsilon_{0}}=120 \pi$ is the intrinsic impedance of the vacuum where $\mu_{0}$ and $\epsilon_{0}$ are the permeability and permittivity of the vacuum, respectively; (ii) $A=\lambda^{2} G_{r} / 4 \pi$ is the effective area of the receiving antenna where $\lambda$ is the wavelength and $G_{r}$ is the gain of the receiving antenna; (iii) $E_{\text {tot }}=\sum_{i} E_{i}$ is the direct field combination between the $\mathrm{Tx}$ and $\mathrm{Rx}$, the fields reflected by the obstacles, the fields transmitted through the obstacles, and the field diffracted by the edge of the obstacles, with

$$
E_{i}=\frac{E_{0} f_{t} f_{r} e^{-j K d}}{d} \prod_{i=1}^{n} R_{i} \prod_{j=1}^{m} T_{j} \prod_{k=1}^{l} D_{k}
$$

where (i) $K$ is the propagation constant; (ii) $E_{0}$ is the reference field; (iii) $f_{t}$ and $f_{r}$ are radiation patterns of the transmitting and receiving antennas, respectively; (iv) $d$ is the length of the path; (v) $n, m$, and $l$ are the total numbers of reflections, transmissions, and diffractions, respectively; (vi) $R_{i}, T_{j}$, and $D_{k}$ are the reflection coefficient of the $i$ th reflection, the transmission coefficient for the $j$ th transmission, and the diffraction coefficient for the $k$ th diffraction, respectively.

The radio channel is represented by its impulse response time-invariant, which is expressed as [15]

$$
h(\tau)=\sum_{i=1}^{N} P_{i} \delta\left(\tau-\tau_{i}\right) e^{j \varphi_{i}}
$$

where $N$ is the received rays number and $P_{i}$ is the power level of the $i$ th path which arrives with a delay $\tau_{i}$ and a phase $\varphi_{i}$ which are calculated by (2) and the length of each path $d$.

The RMS delay spread illustrates the risk of appearance of intersymbol interference, and it is given by [16]

$$
\tau_{\mathrm{RMS}}=\sqrt{\frac{\sum_{i} P_{i} \tau_{i}^{2}}{\sum_{i} P_{i}}-\left[\frac{\sum_{i} P_{i} \tau_{i}}{\sum_{i} P_{i}}\right]^{2}} .
$$

It is now possible to calculate the level of $\mathrm{Pr}$ and RMS delay spread in our indoor environment in the 3 scenarios.

\section{Results and Analyses}

Before presenting the results, the notation $\operatorname{Tx}(0-0)(\mathrm{Rx}(0-0))$ indicates the orientation of the antenna of $\mathrm{Tx}(\mathrm{Rx})$ as shown in Figure 7. The other notations like $\mathrm{Tx}(0-90)(\mathrm{Rx}(0-90))$ are corresponding to a rotation of $90^{\circ}$ along the $\mathrm{OZ}$ axis of $\mathrm{Tx}(0$ $0)(\mathrm{Rx}(0-0))$ with $\mathrm{Tx}(90-0)(\mathrm{Rx}(90-0))$ corresponding to a rotation of $90^{\circ}$ along the axis $O X$ of $\operatorname{Tx}(0-0)(\operatorname{Rx}(0-0))$ and so on.

Regarding the types of polarization to each antenna depending on the orientation, Table 2 lists the types of polarization of each antenna.

3.1. For the LOS Case. The Pr levels which are predicted along the arrow (Figure 6(a)) when using the 3D cubic antenna 

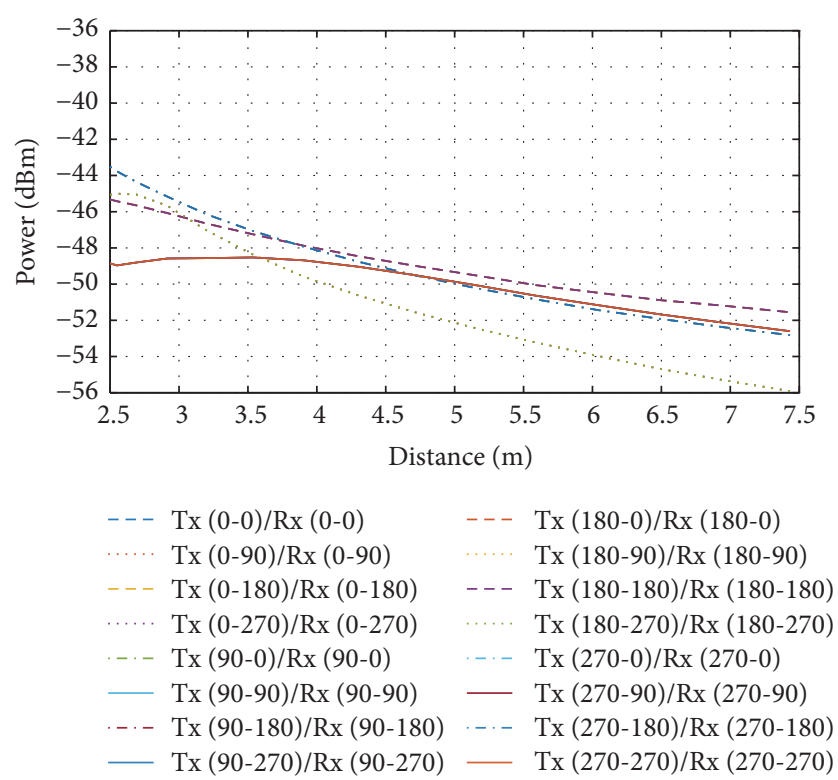

Figure 8: $P r$ levels of the same Tx and Rx orientations using the 3D cubic antenna in the LOS scenario.

TABLE 2: The polarization types of each antenna.

\begin{tabular}{lcc}
\hline \multirow{2}{*}{ Orientations } & \multicolumn{2}{c}{ Polarization of the antenna } \\
& Dipole & 3D cubic \\
\hline $\begin{array}{l}\mathrm{Tx}(0-0)(\mathrm{Rx} \\
(0-0))\end{array}$ & $\begin{array}{c}\text { Vertical linear } \\
(\mathrm{VL})\end{array}$ & $\begin{array}{c}\text { Right circular } \\
(\mathrm{RC})\end{array}$ \\
$\operatorname{Tx}(0-90)(\mathrm{Rx}$ & $\begin{array}{c}\text { Horizontal linear } \\
(0-90))\end{array}$ & Left circular (LC) \\
$\operatorname{Tx}(90-0)(\mathrm{Rx}$ & Vertical linear & Right circular \\
$(90-0))$ & & \\
$\operatorname{Tx}(90-90)(\mathrm{Rx}$ & Horizontal linear & Left circular \\
$(90-90))$ &
\end{tabular}

in both $\mathrm{Tx}$ and Rx with the same orientations are shown in Figure 8.

From the results, we can see only 4 curves of the sum of 16 curves which implies we have identical curves. These curves constitute 4 groups and each group contains 4 curves. The first group of curves is $[\mathrm{Tx}(0-0) / \mathrm{Rx}(0-0), \mathrm{Tx}(0-180) / \mathrm{Rx}(0-$ $180), \operatorname{Tx}(180-0) / \mathrm{Rx}(180-0)$, and $\mathrm{Tx}(180-180) / \mathrm{Rx}(180-180)]$, the second is [ Tx $(0-90) / \mathrm{Rx}(0-90), \mathrm{Tx}(0-270) / \mathrm{Rx}(0-270), \mathrm{Tx}$ $(180-90) / \mathrm{Rx}(180-90), \mathrm{Tx}(180-270) / \mathrm{Rx}(180-270)]$, the third is [Tx (90-0)/Rx (90-0), Tx (270-0)/Rx (270-0), Tx (90-180)/Rx (90-180), and $\mathrm{Tx}(270-180) / \mathrm{Rx}(270-180)]$, and the fourth is [Tx (90-90)/Rx (90-90), Tx (90-270)/Rx (90-270), Tx (27090)/Rx (270-90), and Tx (270-270)/Rx (270-270)].

According to these groups, $\mathrm{Pr}$ from the first combination of $\mathrm{Tx}$ and $\mathrm{Rx}$ is the same after a rotation of $180^{\circ}$ along the $O Z$ axis or along $O X$ or both at the same time, which implies that the radiation pattern of the antenna is symmetrical after one rotation of $180^{\circ}$. So, we will use only the first orientation of each group ((0-0), (0-90), (90-0), and (90-90)). We have in total four combinations of Tx and Rx which have the same orientation. So, we can find six combinations of Tx and

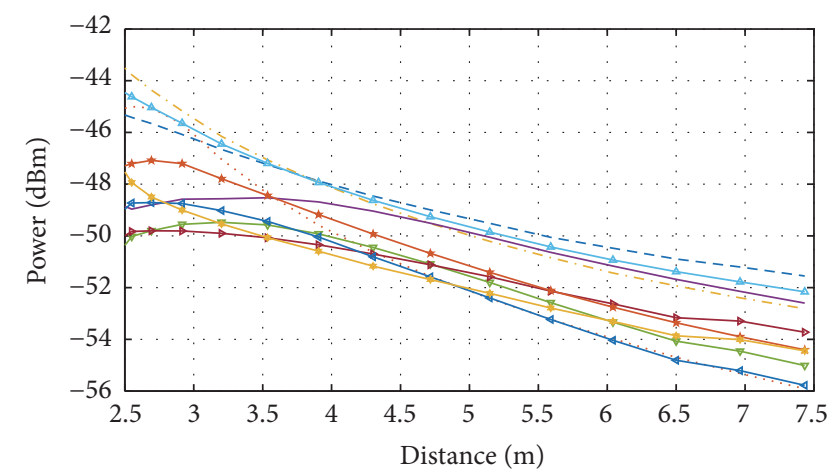

$$
\begin{aligned}
& \text { - - } \operatorname{Tx}(0-0) / \operatorname{Rx}(0-0) \quad \longrightarrow \operatorname{Tx}(90-0) / \mathrm{Rx}(0-0) \\
& \mathrm{Tx}(0-90) / \mathrm{Rx}(0-90) \rightarrow \mathrm{Tx}(90-90) / \mathrm{Rx}(0-0) \\
& \text {-.. } \operatorname{Tx}(90-0) / \mathrm{Rx}(90-0) \_\mathrm{Tx}(90-0) / \mathrm{Rx}(0-90) \\
& \text { — } \operatorname{Tx}(90-90) / \mathrm{Rx}(90-90) \multimap \mathrm{Tx}(90-90) / \mathrm{Rx}(0-90) \\
& \because \mathrm{Tx}(0-90) / \mathrm{Rx}(0-0) \quad \text { } \rightarrow \mathrm{Tx}(90-90) / \mathrm{Rx}(90-0)
\end{aligned}
$$

Figure 9: $\operatorname{Pr}$ levels of all Tx and Rx combinations using the 3D cubic antenna in the LOS scenario.

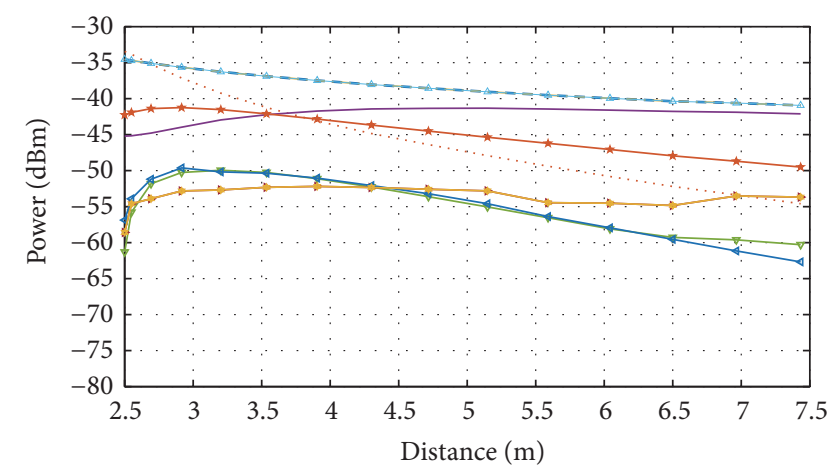

$$
\begin{aligned}
& \text { - - } \operatorname{Tx}(0-0) / \operatorname{Rx}(0-0) \quad \leadsto \operatorname{Tx}(90-0) / \operatorname{Rx}(0-0) \\
& \text {.. } \operatorname{Tx}(0-90) / \mathrm{Rx}(0-90) \rightarrow \operatorname{Tx}(90-90) / \mathrm{Rx}(0-0) \\
& \text {... } \mathrm{Tx}(90-0) / \mathrm{Rx}(90-0) \longleftarrow \mathrm{Tx}(90-0) / \mathrm{Rx}(0-90)
\end{aligned}
$$

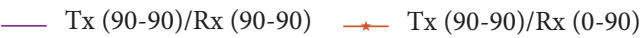

$$
\begin{aligned}
& \rightarrow \mathrm{Tx}(0-90) / \mathrm{Rx}(0-0) \quad \longrightarrow \mathrm{Tx}(90-90) / \mathrm{Rx}(90-0)
\end{aligned}
$$

FIgURE 10: $\operatorname{Pr}$ levels of all Tx and Rx combinations using the dipole antenna in the LOS scenario.

$\mathrm{Rx}$, which have different orientations and different results of $P r$ : [Tx $(0-90) / \mathrm{Rx}(0-0)$, Tx $(90-0) / \mathrm{Rx}(0-0)$, Tx $(90-$ $90) / \operatorname{Rx}(0-0), \operatorname{Tx}(90-0) / \operatorname{Rx}(0-90), \operatorname{Tx}(90-90) / \operatorname{Rx}(0-90)$, and Tx (90-90)/Rx (90-0)]. Figure 9 shows the $\operatorname{Pr}$ levels of all combinations of Tx and Rx using the 3D cubic antenna.

Regarding the results of the $\operatorname{Pr}$ levels when Tx and $\mathrm{Rx}$ use the dipole antenna, Figure 10 shows these levels of all the combinations of Tx and Rx as the preceding case. From this figure, we found identical curves, as follows: (i) Tx $(0-0) / \mathrm{Rx}$ $(0-0)$ with $\mathrm{Tx}(90-0) / \mathrm{Rx}(90-0)$ and $\mathrm{Tx}(90-0) / \mathrm{Rx}(0-0)$ and (ii) $\mathrm{Tx}(90-90) / \mathrm{Rx}(0-0)$ with $\mathrm{Tx}(90-90) / \mathrm{Rx}(90-0)$. This is due to the form of the radiation pattern and the polarization which are symmetrical after a rotation of Tx $(0-0)(\mathrm{Rx}(0-$ $0)$ ) of $90^{\circ}$ along $O X$. We will not cancel the identical curves in order to compare the results with the results found by $3 \mathrm{D}$ cubic antenna. 
TABle 3: Difference between $\operatorname{Pr}$ Max and Min in the LOS scenario.

\begin{tabular}{|c|c|c|c|c|c|c|}
\hline \multirow[b]{2}{*}{ Distance $[\mathrm{m}]$} & \multicolumn{3}{|c|}{ 3D cubic antenna } & \multicolumn{3}{|c|}{ Dipole antenna } \\
\hline & $\begin{array}{c}\operatorname{Pr} \text { Max } \\
{[\mathrm{dBm}]}\end{array}$ & $\begin{array}{c}\operatorname{Pr} \text { Min } \\
{[\mathrm{dBm}]}\end{array}$ & $\begin{array}{c}\text { Diff } \\
{[\mathrm{dBm}]}\end{array}$ & $\begin{array}{c}\operatorname{Pr} \text { Max } \\
{[\mathrm{dBm}]}\end{array}$ & $\begin{array}{c}\operatorname{Pr} \text { Min } \\
{[\mathrm{dBm}]}\end{array}$ & $\begin{array}{c}\text { Diff } \\
{[\mathrm{dBm}]}\end{array}$ \\
\hline 2.5 & -43.51 & -50.36 & 6.85 & -33.44 & -61.31 & 27.87 \\
\hline 2.55 & -43.77 & -50.02 & 6.25 & -33.82 & -55.77 & 21.95 \\
\hline 2.7 & -44.36 & -49.8 & 5.44 & -35.09 & -53.9 & 18.81 \\
\hline 2.9 & -45.16 & -49.81 & 4.65 & -35.65 & -52.82 & 17.17 \\
\hline 3.2 & -46.14 & -49.9 & 3.76 & -36.26 & -52.68 & 16.42 \\
\hline 3.54 & -47.06 & -50.07 & 3.01 & -36.88 & -52.32 & 15.44 \\
\hline 3.9 & -47.87 & -50.59 & 2.72 & -37.48 & -52.18 & 14.7 \\
\hline 4.3 & -48.46 & -51.16 & 2.7 & -38.03 & -52.33 & 14.3 \\
\hline 4.72 & -48.99 & -51.68 & 2.69 & -38.56 & -53.61 & 15.05 \\
\hline 5.15 & -49.51 & -52.42 & 2.91 & -39.04 & -55.04 & 16 \\
\hline 5.6 & -50.05 & -53.23 & 3.18 & -39.52 & -56.54 & 17.02 \\
\hline 6.05 & -50.47 & -54.03 & 3.56 & -39.95 & -58.09 & 18.14 \\
\hline 6.5 & -50.89 & -54.8 & 3.91 & -40.36 & -59.54 & 19.18 \\
\hline 6.96 & -51.2 & -55.32 & 4.12 & -40.61 & -61.15 & 20.54 \\
\hline 7.43 & -51.55 & -55.9 & 4.35 & -40.94 & -62.67 & 21.73 \\
\hline
\end{tabular}

To find the difference between the orientation of the two antennas in the LOS scenario according to the $\operatorname{Pr}$ levels, Table 3 presents the maximum and minimum values of $\mathrm{Pr}$ of all $\mathrm{Tx}$ and $\mathrm{Rx}$ combinations of each antenna and the difference between them.

From Figures 9 and 10 and Table 3, we observe that, in the case of using the $3 \mathrm{D}$ cubic antenna, the $\operatorname{Pr}$ levels are greater than $-56 \mathrm{dBm}$, and when using the dipole antenna, it is greater than $-63 \mathrm{dBm}$. We also observe that the curves of Figure 9 are crossed with each other, and this proves that we can find a small difference between the $\operatorname{Pr}$ levels of each orientation. However, in Figure 10, only two curves are interlaced. As we can see from the table, the large difference between all combinations of the dipole antenna is $27.81 \mathrm{dBm}$ between the combinations $\mathrm{Tx}(0-90) / \mathrm{Rx}(0-90)$ (i.e., HL/HL) and $\mathrm{Tx}(0-90) / \mathrm{Rx}(0-0)$ (i.e., HL/VL). In [8], the power difference between the same polarization (VL/VL) and different polarization (VL/HL) combinations is greater than $30 \mathrm{dBm}$ in the LOS scenario. So, the value that we found is not surprising. Regarding the $3 \mathrm{D}$ cubic antenna, the big difference that we found is $6.85 \mathrm{dBm}$ between the combinations $\mathrm{Tx}(90-0) / \mathrm{Rx}(90-0)$ (i.e., RC/RC) and $\mathrm{Tx}$ $(0-90) / \mathrm{Rx}(0-0)$ (i.e., LC/RC). We note that the two large values are found between $\mathrm{Tx}$ and $\mathrm{Rx}$ which have the same polarization and those that have different polarization. The difference of the power found in the case of using the $3 \mathrm{D}$ cubic antenna is very much lower than the case when using the dipole antenna.

Regarding the RMS delay spread, its results along the arrow of each orientation of the two antennas in the LOS scenario are shown in Figure 11.

To find the difference between the orientations of the two antennas in terms of the levels of the RMS delay spread in the LOS scenario, Table 4 presents the values of the maximum and minimum RMS delay spread and the difference between them of each antenna.

From Figure 11 and Table 4, the RMS levels in the case of using the 3D cubic antenna do not exceed 12 ns. However, in the case of using the dipole antenna, the RMS levels reach $28.49 \mathrm{~ns}$. The high value of the difference between the maximum and minimum RMS of the dipole antenna and that of $3 \mathrm{D}$ cubic antenna is $25.06 \mathrm{~ns}$ and $6.48 \mathrm{~ns}$, respectively. In [8], the authors found that the difference between the RMS of the Tx and Rx combinations using the dipole antenna is about $15 \mathrm{~ns}$. So, the value that we found is a little big but they are both higher (due to the frequency and environment used). To conclude, the difference of the RMS found in the case of using the $3 \mathrm{D}$ cubic antenna is much lower than the case of using the dipole antenna.

3.2. For the NLOS Case. Table 5 presents the maximum and minimum values of $\mathrm{Pr}$ and the difference between them found from Figure 12 which presents the $\operatorname{Pr}$ levels of all Tx and Rx orientations in the NLOS scenario.

From Figure 12, we notice that in both cases of using the 3D cubic antenna and the dipole antenna, the $\operatorname{Pr}$ levels are lower than the $\operatorname{Pr}$ levels in the LOS case, and this is normal because we do not have a direct visibility between Tx and $\mathrm{Rx}$. In the case of using the 3D cubic antenna, the big difference between all the combinations is $6.07 \mathrm{dBm}$ (between Tx and $\mathrm{Rx}$ which have the same and different polarization). In the case of using the dipole antenna, the large difference in power between all combinations is $25.08 \mathrm{dBm}$ (between $\mathrm{Tx}$ and $\mathrm{Rx}$ which have the same polarization and different polarization). So, the difference found in the case of using the dipole antenna is much greater than the case when using the 3D cubic antenna. In [8], the authors did not treat the case when the Tx and $\mathrm{Rx}$ are in different rooms, that is, the NLOS scenario. So, we cannot compare the results. 


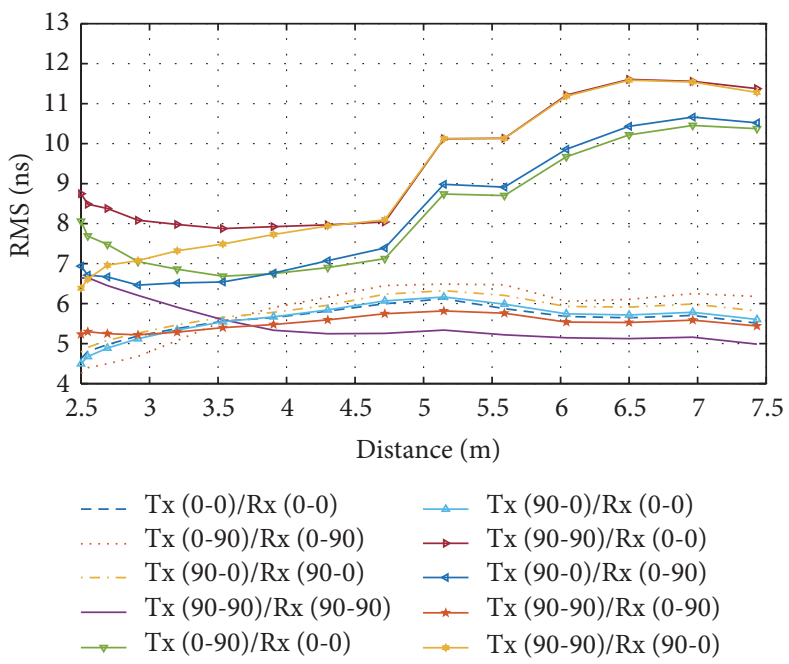

(a)

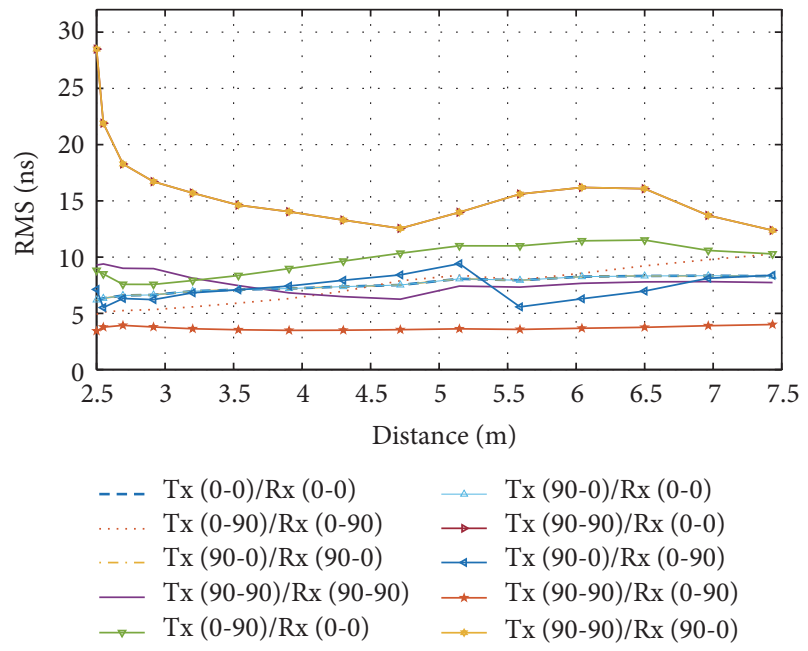

(b)

FIGURE 11: RMS delay spread for the two antennas in the LOS scenario: (a) 3D cubic antenna and (b) dipole antenna.

TABLE 4: Difference between RMS Max and Min in the LOS scenario.

\begin{tabular}{|c|c|c|c|c|c|c|}
\hline \multirow[b]{2}{*}{ Distance $[\mathrm{m}]$} & \multicolumn{3}{|c|}{ 3D cubic antenna } & \multicolumn{3}{|c|}{ Dipole antenna } \\
\hline & $\begin{array}{c}\text { RMS Max } \\
{[\mathrm{ns}]}\end{array}$ & $\begin{array}{l}\text { RMS Min } \\
\text { [ns] }\end{array}$ & $\begin{array}{l}\text { Diff } \\
{[\mathrm{ns}]}\end{array}$ & $\begin{array}{c}\text { RMS Max } \\
\text { [ns] }\end{array}$ & $\begin{array}{l}\text { RMS Min } \\
{[\mathrm{ns}]}\end{array}$ & $\begin{array}{l}\text { Diff } \\
{[\mathrm{ns}]}\end{array}$ \\
\hline 2.5 & 8.74 & 4.25 & 4.49 & 28.49 & 3.43 & 25.06 \\
\hline 2.55 & 8.48 & 4.39 & 4.09 & 21.9 & 3.77 & 18.13 \\
\hline 2.7 & 8.37 & 4.49 & 3.88 & 18.27 & 3.93 & 14.34 \\
\hline 2.9 & 8.08 & 4.68 & 3.4 & 16.7 & 3.78 & 12.92 \\
\hline 3.2 & 7.98 & 5.07 & 2.91 & 15.69 & 3.62 & 12.07 \\
\hline 3.54 & 7.87 & 5.39 & 2.48 & 14.62 & 3.54 & 11.08 \\
\hline 3.9 & 7.92 & 5.33 & 2.59 & 14.03 & 3.48 & 10.55 \\
\hline 4.3 & 7.96 & 5.24 & 2.72 & 13.29 & 3.5 & 9.79 \\
\hline 4.72 & 8.09 & 5.25 & 2.84 & 12.55 & 3.55 & 9 \\
\hline 5.15 & 10.12 & 5.33 & 4.79 & 13.98 & 3.62 & 10.36 \\
\hline 5.6 & 10.13 & 5.21 & 4.92 & 15.6 & 3.57 & 12.03 \\
\hline 6.05 & 11.21 & 5.14 & 6.07 & 16.18 & 3.67 & 12.51 \\
\hline 6.5 & 11.6 & 5.12 & 6.48 & 16.07 & 3.75 & 12.32 \\
\hline 6.96 & 11.55 & 5.16 & 6.39 & 13.7 & 3.9 & 9.8 \\
\hline 7.43 & 11.37 & 4.98 & 6.39 & 12.38 & 4 & 8.38 \\
\hline
\end{tabular}

The results of the RMS delay spread for each orientation of the two antennas in the NLOS scenario are shown in Figure 13. The maximum and minimum RMS delay spread values and the difference between them of all combinations of each antenna are listed in Table 6.

From Figure 13 and Table 6, we observe that the RMS delay spread levels in the case of using the 3D cubic antenna do not exceed $11 \mathrm{~ns}$. However, in the case of using the dipole antenna, the RMS delay spread levels reach $26.46 \mathrm{~ns}$. The difference between the maximum and minimum RMS delay spread of all 3D cubic antenna locations and combinations varies from $2.49 \mathrm{~ns}$ to $4.64 \mathrm{~ns}$. In the case of using the dipole antenna, the difference varies from $6.71 \mathrm{~ns}$ to $23.62 \mathrm{~ns}$. We always find that the use of the dipole antenna gives a big difference from the RMS delay spread even if it is small difference, and it is greater than the big difference found by using 3D cubic antenna.

3.3. For the OLOS Case. The Pr levels and the difference between maximum and minimum $\mathrm{Pr}$ in OLOS scenario of the two antennas are presented in Figure 14 and Table 7, respectively.

From Figure 14 and Table 7, we observe that the $\operatorname{Pr}$ levels in the case of using the $3 \mathrm{D}$ cubic antenna are greater than $-65 \mathrm{dBm}$. However, in the case of using the dipole antenna the levels are greater than $-73 \mathrm{dBm}$. The big difference of 


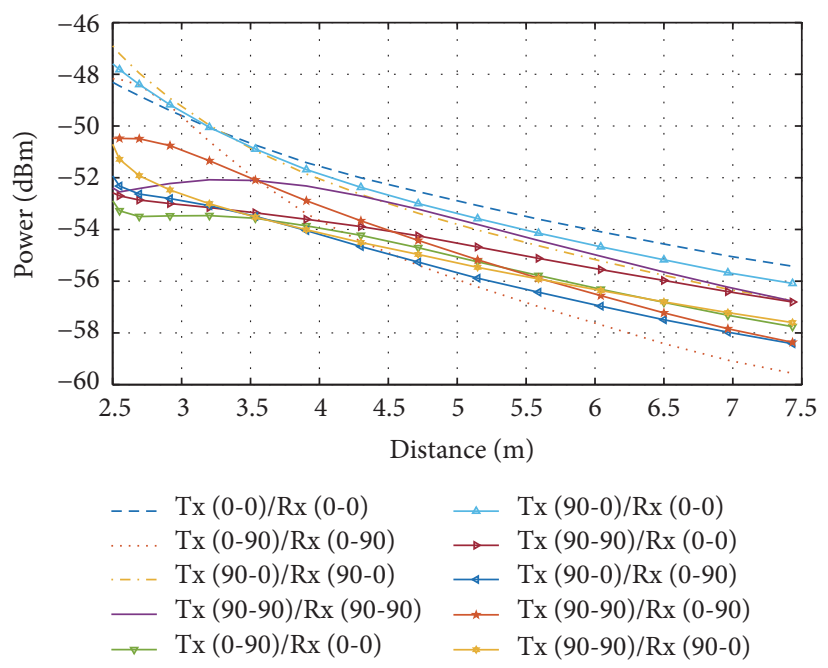

(a)

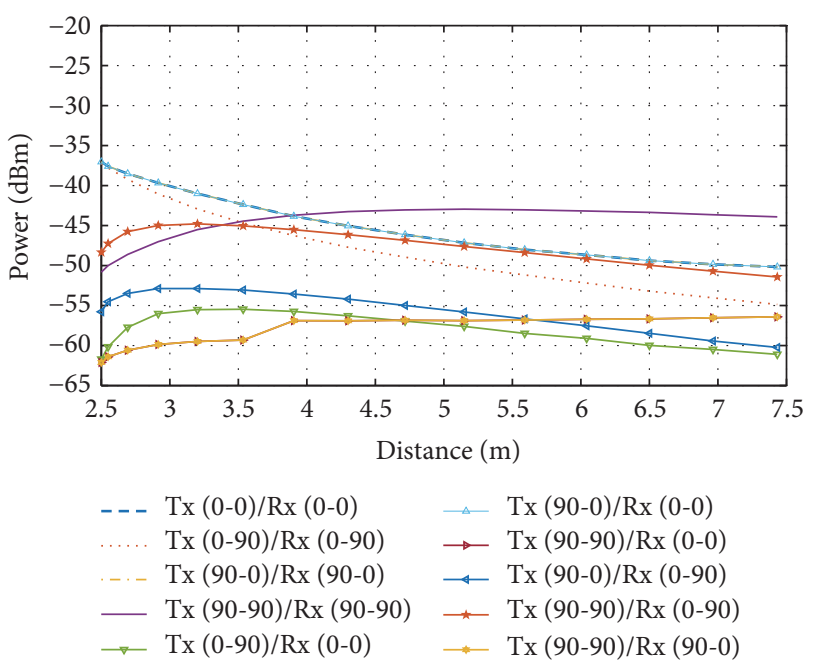

(b)

Figure 12: $\operatorname{Pr}$ levels for both antennas in the NLOS scenario: (a) 3D cubic antenna and (b) dipole antenna.

TABle 5: Difference between $\operatorname{Pr}$ Max and Min in the NLOS scenario.

\begin{tabular}{|c|c|c|c|c|c|c|}
\hline \multirow[b]{2}{*}{ Distance $[\mathrm{m}]$} & \multicolumn{3}{|c|}{ 3D cubic antenna } & \multicolumn{3}{|c|}{ Dipole antenna } \\
\hline & $\begin{array}{c}\operatorname{Pr} \text { Max } \\
{[\mathrm{dBm}]}\end{array}$ & $\begin{array}{c}\operatorname{Pr} \text { Min } \\
{[\mathrm{dBm}]}\end{array}$ & $\begin{array}{c}\text { Diff } \\
{[\mathrm{dBm}]}\end{array}$ & $\begin{array}{c}\operatorname{Pr} \text { Max } \\
{[\mathrm{dBm}]}\end{array}$ & $\begin{array}{c}\operatorname{Pr} \text { Min } \\
{[\mathrm{dBm}]}\end{array}$ & $\begin{array}{c}\text { Diff } \\
{[\mathrm{dBm}]}\end{array}$ \\
\hline 2.5 & -46.89 & -52.88 & 5.99 & -37.03 & -62.11 & 25.08 \\
\hline 2.55 & -47.2 & -53.27 & 6.07 & -37.59 & -61.39 & 23.8 \\
\hline 2.7 & -47.95 & -53.5 & 5.55 & -38.51 & -60.57 & 22.06 \\
\hline 2.9 & -48.92 & -53.47 & 4.55 & -39.66 & -59.86 & 20.2 \\
\hline 3.2 & -49.97 & -53.46 & 3.49 & -41 & -59.48 & 18.48 \\
\hline 3.54 & -50.73 & -53.56 & 2.83 & -42.37 & -59.3 & 16.93 \\
\hline 3.9 & -51.41 & -54.04 & 2.63 & -43.71 & -56.88 & 13.17 \\
\hline 4.3 & -52 & -54.65 & 2.65 & -43.25 & -56.9 & 13.65 \\
\hline 4.72 & -52.53 & -55.38 & 2.85 & -43.04 & -56.93 & 13.89 \\
\hline 5.15 & -53.07 & -56.22 & 3.15 & -42.95 & -57.6 & 14.65 \\
\hline 5.6 & -53.6 & -56.98 & 3.38 & -43.03 & -58.47 & 15.44 \\
\hline 6.05 & -54.09 & -57.68 & 3.59 & -43.18 & -59.1 & 15.92 \\
\hline 6.5 & -54.56 & -58.41 & 3.85 & -43.34 & -59.97 & 16.63 \\
\hline 6.96 & -55.02 & -59.05 & 4.03 & -43.64 & -60.48 & 16.84 \\
\hline 7.43 & -55.42 & -59.56 & 4.14 & -43.9 & -61.1 & 17.2 \\
\hline
\end{tabular}

the $\operatorname{Pr}$ between all the combinations of the dipole antenna that we found is $27.97 \mathrm{dBm}$. In [8] the authors found that the difference between the $\mathrm{Pr}$ of $\mathrm{Tx}$ and $\mathrm{Rx}$ combinations using the dipole antenna is greater than $30 \mathrm{dBm}$ in the OLOS scenario. So, the great value that we found is not surprising. However, the big difference of the $\operatorname{Pr}$ between all the combinations of $3 \mathrm{D}$ cubic antenna that we found is $4.6 \mathrm{dBm}$. So, the power difference in the case of using the dipole antenna is much higher than the case when using the $3 \mathrm{D}$ cube antenna.

Regarding RMS delay spread, Table 8 shows the maximum and minimum RMS values and the difference between them of all the combinations of each antenna found from
Figure 15 which presents the RMS delay spread results along the arrow in the OLOS scenario.

From Figure 13 and Table 6, we observe that the levels of all the RMS delay spread in the case of using the $3 \mathrm{D}$ cubic antenna do not exceed $22 \mathrm{~ns}$; however, in the case of using the dipole antenna, the RMS delay spread levels reach $32.84 \mathrm{~ns}$. These two worst values of the RMS delay spread are found by the two antennas because there is a great excess delay due to multiple reflections, transmissions, and diffractions. The difference between the maximum and minimum RMS of all dipole antenna locations and combinations varies from $17.35 \mathrm{~ns}$ to $27.97 \mathrm{~ns}$. In [8], the authors found that the difference between the RMS of the dipole antenna combinations is 

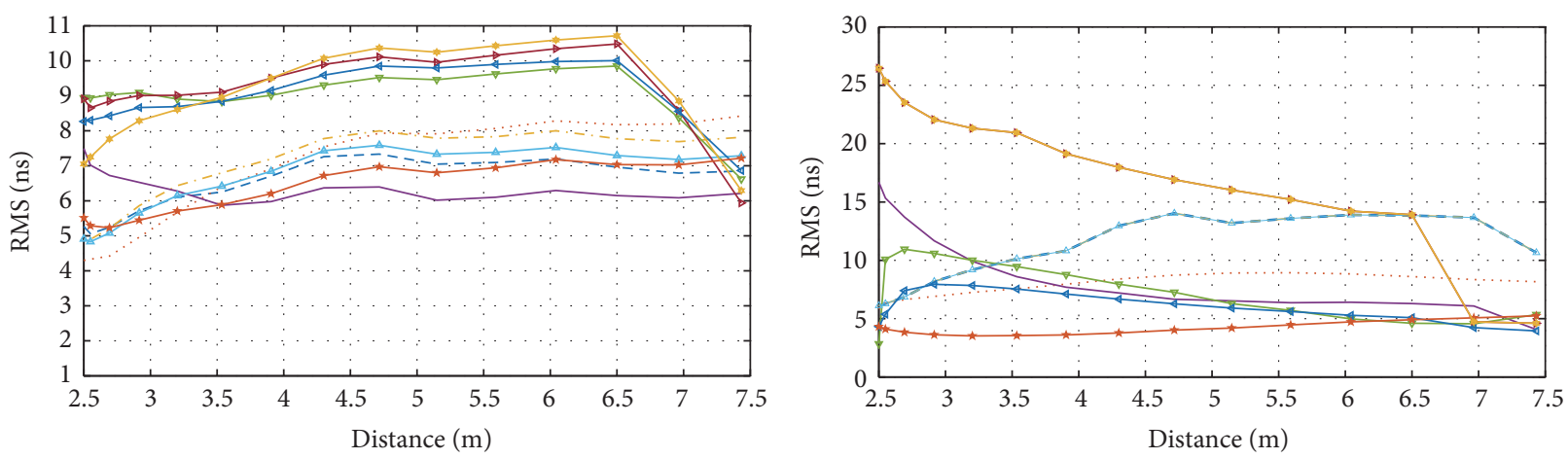

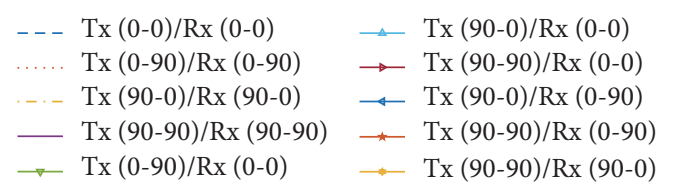

(a)

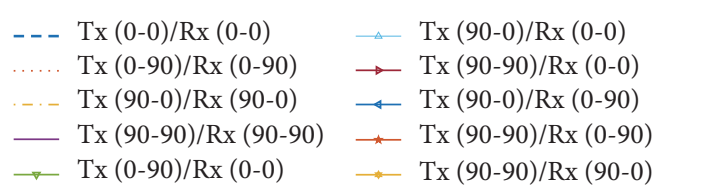

(b)

FIGURE 13: RMS delay spread for the two antennas in the NLOS scenario: (a) 3D cubic antenna and (b) dipole antenna.

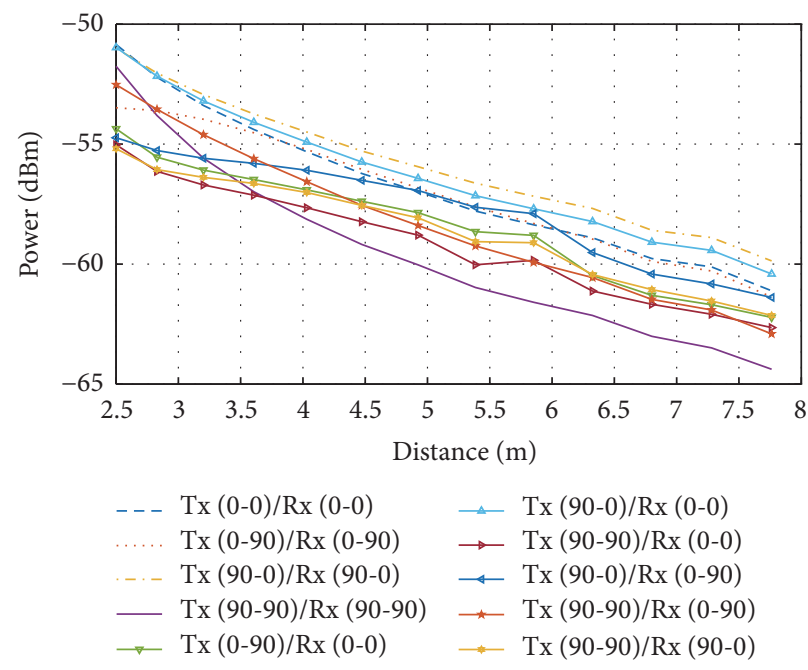

(a)

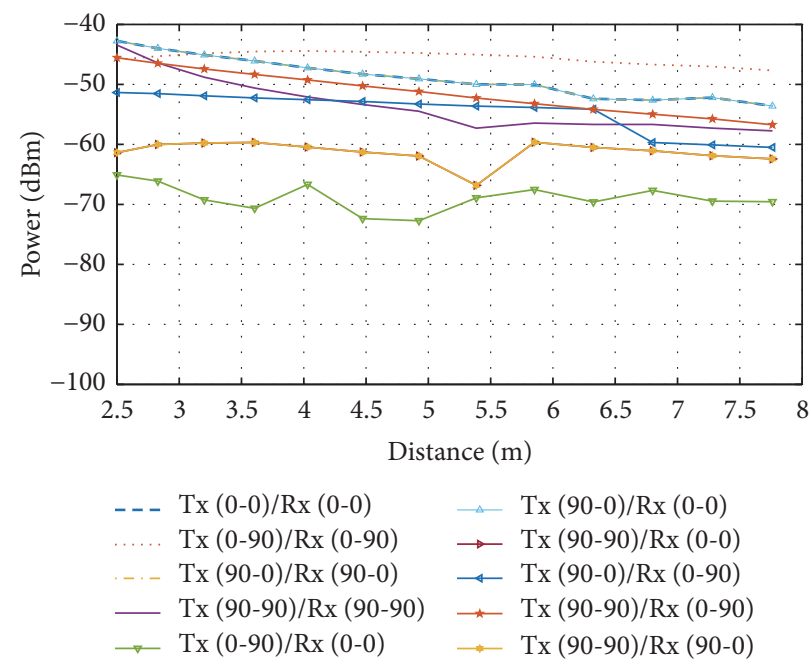

(b)

FIgURE 14: $\operatorname{Pr}$ level for both antennas in the OLOS scenario: (a) 3D cubic antenna and (b) dipole antenna.

about 19 ns. So, the great value that we found is a bit higher (due to the frequency and environment used) but they are both great. However, in the case of using the 3D cubic antenna the difference varies from $5.16 \mathrm{~ns}$ to $9.34 \mathrm{~ns}$. We always find that the use of the dipole antenna gives a big difference of the RMS delay spread.

In all LOS, NLOS, and OLOS environment scenarios, the orientation of both $\mathrm{Tx}$ and $\mathrm{Rx}$ using the dipole antenna gives a large difference between the $P r$ levels due to the anisotropy of the antenna radiation and the linear polarization mismatch (HL-VL). The orientation of both Tx and Rx using the 3D cubic antenna gives a small difference between the $\operatorname{Pr}$ levels due to the quasi-isotropy of the antenna radiation and the low circular polarization mismatch (RC-LG), because the direction of circular polarization changes after each reflection and each diffraction. So, we can deduce that the $\operatorname{Pr}$ is very dependent on the radiation pattern and the type of polarization of the antenna and the environment.

Regarding the RMS delay spread, the orientation of both Tx and $\mathrm{Rx}$ using the dipole antenna gives a big difference between the RMS in all LOS, NLOS, and OLOS environment scenarios. This is due to the large and the small excess delay owing to the form of the radiation pattern and the linear polarization. The low values of the difference between the RSM are obtained by using the $3 \mathrm{D}$ cubic antenna due to a circular polarization and the quasi-isotropy of the radiation.

\section{Conclusion}

In this work, we studied the effect of the orientation of two different antennas on the propagation characteristics such as the received power $(P r)$ and the RMS delay spread. The 

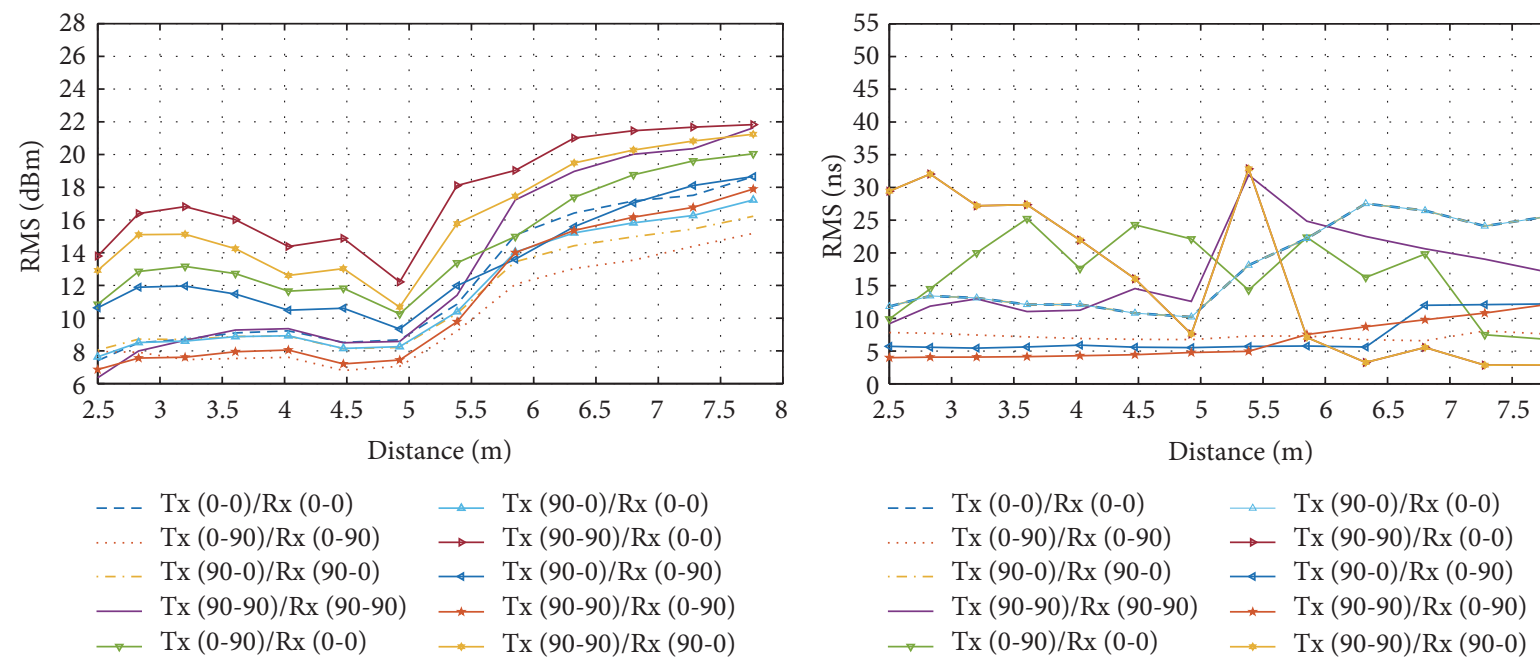

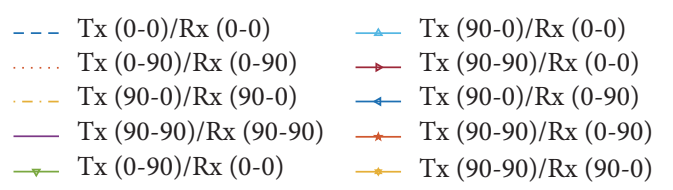

(a)

(b)

FIGURE 15: RMS delay spread for the two antennas in the OLOS scenario: (a) 3D cubic antenna and (b) dipole antenna.

TABLE 6: Difference between RMS Max and Min in the NLOS scenario.

\begin{tabular}{|c|c|c|c|c|c|c|}
\hline \multirow[b]{2}{*}{ Distance $[\mathrm{m}]$} & \multicolumn{3}{|c|}{ 3D cubic antenna } & \multicolumn{3}{|c|}{ Dipole antenna } \\
\hline & $\begin{array}{c}\text { RMS Max } \\
\text { [ns] }\end{array}$ & $\begin{array}{c}\text { RMS Min } \\
\text { [ns] }\end{array}$ & $\begin{array}{l}\text { Diff } \\
{[\mathrm{ns}]}\end{array}$ & $\begin{array}{c}\text { RMS Max } \\
\text { [ns] }\end{array}$ & $\begin{array}{c}\text { RMS Min } \\
\text { [ns] }\end{array}$ & $\begin{array}{l}\text { Diff } \\
{[\mathrm{ns}]}\end{array}$ \\
\hline 2.5 & 8.93 & 4.29 & 4.64 & 26.46 & 2.84 & 23.62 \\
\hline 2.55 & 8.93 & 4.32 & 4.61 & 25.35 & 4.11 & 21.24 \\
\hline 2.7 & 9.02 & 4.42 & 4.6 & 23.52 & 3.83 & 19.69 \\
\hline 2.9 & 9.09 & 4.95 & 4.14 & 22.05 & 3.62 & 18.43 \\
\hline 3.2 & 9.01 & 5.67 & 3.34 & 21.31 & 3.52 & 17.79 \\
\hline 3.54 & 9.1 & 5.87 & 3.23 & 20.93 & 3.54 & 17.39 \\
\hline 3.9 & 9.5 & 5.97 & 3.53 & 19.13 & 3.6 & 15.53 \\
\hline 4.3 & 10.07 & 6.37 & 3.7 & 17.97 & 3.77 & 14.2 \\
\hline 4.72 & 10.36 & 6.39 & 3.97 & 16.91 & 4.02 & 12.89 \\
\hline 5.15 & 10.24 & 6.01 & 4.23 & 16.02 & 4.2 & 11.82 \\
\hline 5.6 & 10.42 & 6.1 & 4.32 & 15.21 & 4.46 & 10.75 \\
\hline 6.05 & 10.59 & 6.29 & 4.3 & 14.21 & 4.72 & 9.49 \\
\hline 6.5 & 10.71 & 6.14 & 4.57 & 13.91 & 4.61 & 9.3 \\
\hline 6.96 & 8.85 & 6.08 & 2.77 & 13.66 & 4.23 & 9.43 \\
\hline 7.43 & 8.42 & 5.93 & 2.49 & 10.66 & 3.95 & 6.71 \\
\hline
\end{tabular}

first antenna is a dipole one which produces omnidirectional radiation with linear polarization and the second is a cubic $3 \mathrm{D}$ antenna which produces a quasi-isotropic radiation with a circular polarization. The study has been made in three different scenarios of the indoor environment (LOS, NLOS, and OLOS) by computer simulations based on the 3D raytracing method. On the one hand, we have found in all the environment scenarios that there is a small difference between the $\operatorname{Pr}$ levels and also a small difference between the RMS levels depending on the orientation of the $3 \mathrm{D}$ cubic antenna and this is due to the quasi-isotropy of the antenna radiation and the low circular polarization mismatch. On the other hand, the orientations of the dipole antenna lead to a big difference between the $P r$ and the RMS due to the anisotropy of the antenna radiation and the strong linear polarization mismatch. We can conclude that the effect of the orientation of the cubic 3D antenna has a small influence on the propagation characteristics channel ( $P r$ and RMS) compared to the dipole antenna. Consequently, we can deploy the nodes of the RFID sensor network (RSN) using the 3D cubic antenna in a random manner instead of the dipole antenna which is used a lot. For a future work, we will do the same study using this time the 3D spherical antenna that we designed in [17] which produces a quasi-isotropic radiation diagram with $360^{\circ}$ of opening angle in the whole space. 
TABle 7: Difference between $\operatorname{Pr}$ Max and Min in the OLOS scenario.

\begin{tabular}{lccccc}
\hline & \multicolumn{3}{c}{ 3D cubic antenna } & \multicolumn{2}{c}{ Dipole antenna } \\
Distance $[\mathrm{m}]$ & $\begin{array}{c}\operatorname{Pr} \text { Max } \\
{[\mathrm{dBm}]}\end{array}$ & {$[\mathrm{dBm}]$} & $\begin{array}{c}\text { Diff } \\
{[\mathrm{dBm}]}\end{array}$ & $\begin{array}{c}\operatorname{Pr} \text { Max } \\
{[\mathrm{dBm}]}\end{array}$ & $\begin{array}{c}\text { Minf } \\
{[\mathrm{dBm}]}\end{array}$ \\
\hline 2.5 & -50.85 & -55.19 & 4.34 & $-42,75$ & $-65,09$ \\
{$[\mathrm{dBm}]$}
\end{tabular}

TABLE 8: Difference between RMS Max and Min in the OLOS scenario.

\begin{tabular}{|c|c|c|c|c|c|c|}
\hline \multirow[b]{2}{*}{ Distance $[\mathrm{m}]$} & \multicolumn{3}{|c|}{ 3D cubic antenna } & \multicolumn{3}{|c|}{ Dipole antenna } \\
\hline & $\begin{array}{c}\text { RMS Max } \\
{[\mathrm{dBm}]}\end{array}$ & $\begin{array}{c}\text { RMS Min } \\
{[\mathrm{dBm}]}\end{array}$ & $\begin{array}{c}\text { Diff } \\
{[\mathrm{dBm}]}\end{array}$ & $\begin{array}{c}\text { RMS Max } \\
{[\mathrm{dBm}]}\end{array}$ & $\begin{array}{c}\text { RMS Min } \\
{[\mathrm{dBm}]}\end{array}$ & $\begin{array}{c}\text { Diff } \\
{[\mathrm{dBm}]}\end{array}$ \\
\hline 2.5 & 13.79 & 6.36 & 7.43 & 29.43 & 3.98 & 25.45 \\
\hline 2.83 & 16.39 & 7.56 & 8.83 & 32.04 & 4.07 & 27.97 \\
\hline 3.2 & 16.81 & 7.47 & 9.34 & 27.19 & 4.08 & 23.11 \\
\hline 3.6 & 16.01 & 7.53 & 8.48 & 27.36 & 4.15 & 23.21 \\
\hline 4.03 & 14.37 & 7.6 & 6.77 & 21.96 & 4.28 & 17.68 \\
\hline 4.47 & 14.88 & 6.8 & 8.08 & 24.29 & 4.44 & 19.85 \\
\hline 4.92 & 12.21 & 7.05 & 5.16 & 22.13 & 4.78 & 17.35 \\
\hline 5.38 & 18.1 & 9.2 & 8.9 & 32.84 & 4.96 & 27.88 \\
\hline 5.85 & 19.03 & 12.07 & 6.96 & 24.85 & 5.77 & 19.08 \\
\hline 6.32 & 21.01 & 13.03 & 7.98 & 27.52 & 3.25 & 24.27 \\
\hline 6.8 & 21.45 & 13.54 & 7.91 & 26.45 & 5.55 & 20.9 \\
\hline 7.28 & 21.67 & 14.39 & 7.28 & 24.09 & 2.85 & 21.24 \\
\hline 7.76 & 21.82 & 15.17 & 6.65 & 25.49 & 2.89 & 22.6 \\
\hline
\end{tabular}

\section{Conflicts of Interest}

The authors declare that they have no conflicts of interest.

\section{References}

[1] M. Bolić, D. Simplot-Ryl, and I. Stojmenović, "RFID Systems: Research Trends and Challenges," RFID Systems: Research Trends and Challenges, 2010.

[2] Q. Wang and I. Balasingham, Wireless Sensor Networks-An Introduction, Wireless Sensor Networks: Application-Centric Design, Yen Kheng Tan, 2010.

[3] A. W. Nagpurkar and S. K. Jaiswal, "An overview of WSN and RFID network integration," in Proceedings of 2nd International Conference on Electronics and Communication Systems, ICECS 2015, pp. 497-502, ind, February 2015.
[4] L. Wang, L. D. Xu, Z. Bi, and Y. Xu, "Data cleaning for RFID and WSN integration," IEEE Transactions on Industrial Informatics, vol. 10, no. 1, pp. 408-418, 2014.

[5] F. M. Al-Turjman, A. E. Al-Fagih, and H. S. Hassanein, "A novel cost-effective architecture and deployment strategy for integrated RFID and WSN systems," in Proceedings of the International Conference on Computing, Networking and Communications (ICNC '12), pp. 835-839, Maui, Hawaii, USA, January 2012.

[6] B. Zhang, K. Hu, and Y. Zhu, "Network architecture and energy analysis of the integration of RFID and wireless sensor network," in Proceedings of the Chinese Control and Decision Conference (CCDC '10), pp. 1379-1382, May 2010.

[7] T. Manabe, Y. Miura, and T. Ihara, "Effects of antenna directivity and polarization on indoor multipath propagation characteristics at $60 \mathrm{GHz}$," IEEE Journal on Selected Areas in Communications, vol. 14, no. 3, pp. 441-447, 1996. 
[8] Z.-Y. Liu, L.-X. Guo, and C.-L. Li, "Effects of antenna polarization on power and RMS delay spread in LOS/OOS indoor radio channel," in Proceedings of 31st General Assembly and Scientific Symposium of the International Union of Radio Science, URSI GASS 2014, chn, August 2014.

[9] A. Bou-El-Harmel, A. Benbassou, and J. Belkadid, "Design of a three-dimensional antenna UHF in the form cubic intended for RFID, wireless sensor networks (WSNs) and RFID sensor networks (RSNs) applications," International Journal on Communications Antenna and Propagation, vol. 4, no. 6, pp. 260264, 2014.

[10] A. Bou-El-Harmel, A. Benbassou, and J. Belkadid, "Optimization of a 3D UHF cubic antenna with quasi-isotropic radiation pattern for RFID, WSN and RSN applications," WSEAS Transactions on Communications, vol. 14, no. 42, pp. 365-373, 2015.

[11] C.-F. Yang, C.-J. Ko, and B.-C. Wu, "A free space approach for extracting the equivalent dielectric constants of the walls in buildings," in Proceedings of IEEE Antennas and Propagation Society International Symposium, pp. 1036-1039, IEEE, Baltimore, MD, USA, July 1996.

[12] O. N. Stavroudis, The Mathematics of Geometrical and Physical Optics, John Wiley \& Sons, 2006.

[13] J. Russell and C. Ronald, Uniform Theory of Diffraction, Book on Demand, 2012.

[14] Z.-Y. Liu, L.-X. Guo, and X. Meng, "Efficient three-dimensional ray-tracing model for electromagnetic propagation prediction in complex indoor environments," Journal of the Optical Society of America A: Optics and Image Science, and Vision, vol. 30, no. 8, pp. 1654-1660, 2013.

[15] Y. Wang, W. Lu, and H. Zhu, "Experimental study on indoor channel model for wireless sensor networks and Internet of Things," in Proceedings of 2010 IEEE 12th International Conference on Communication Technology, ICCT'2010, pp. 624-627, chn, November 2010.

[16] S. Priebe, M. Jacob, and T. Kürner, "Angular and RMS delay spread modeling in view of THz indoor communication systems," Radio Science, vol. 49, no. 3, pp. 242-251, 2014.

[17] A. Bou-El-Harmel, A. Benbassou, and J. Belkadid, "Design and development of a new electrically small 3D UHF spherical antenna with 360。 of opening angle in the whole space for RFiD, WSN, and RSN applications," International Journal of Antennas and Propagation, vol. 2016, Article ID 2906149, pp. 1-18, 2016. 


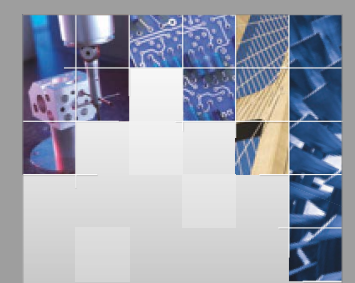

\section{Enfincering}
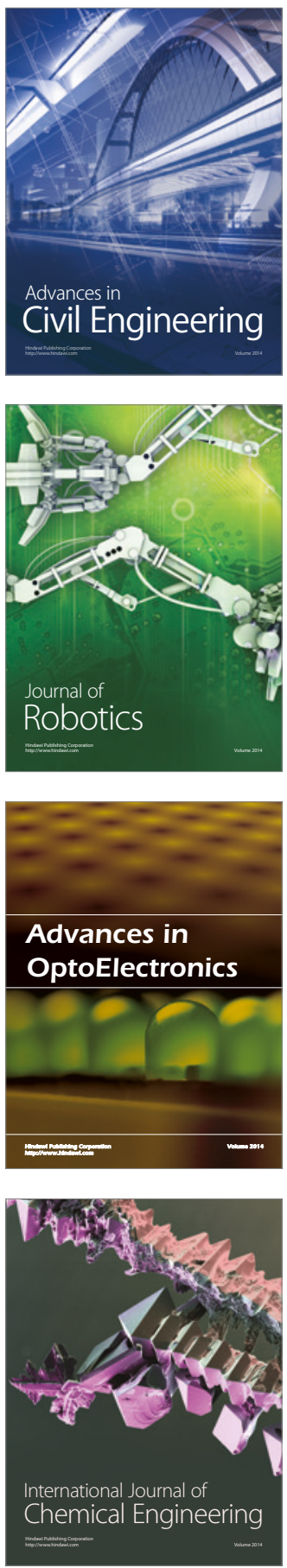

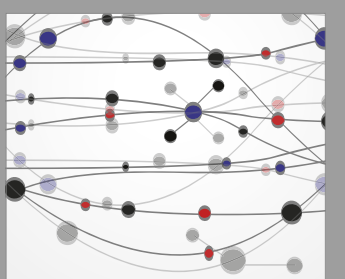

The Scientific World Journal

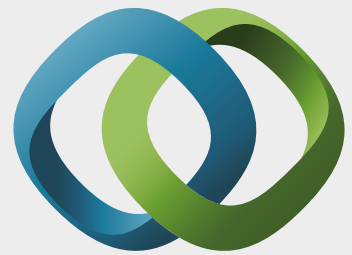

\section{Hindawi}

Submit your manuscripts at

https://www.hindawi.com
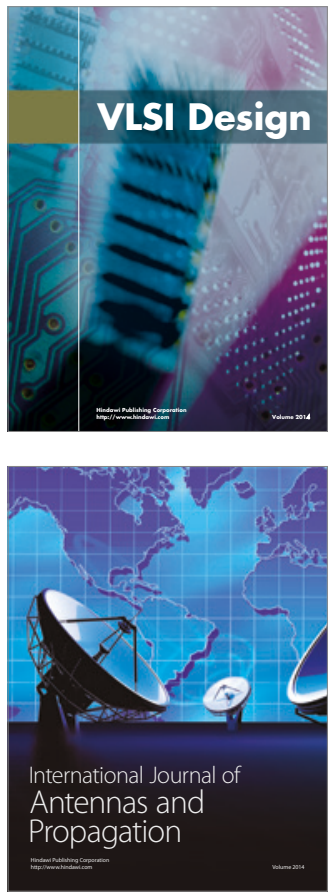

\section{Rotating}

Machinery
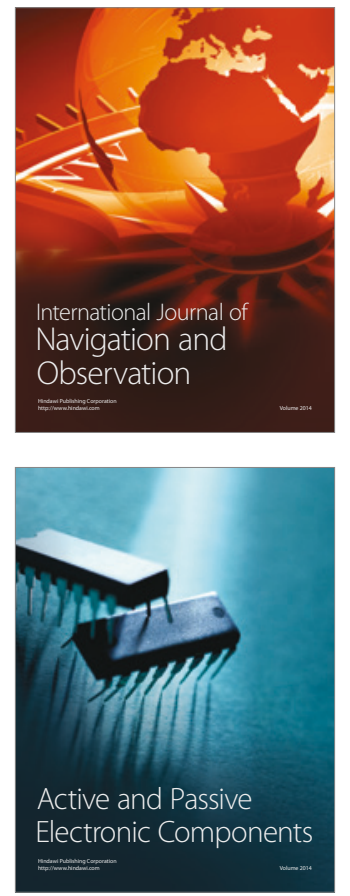
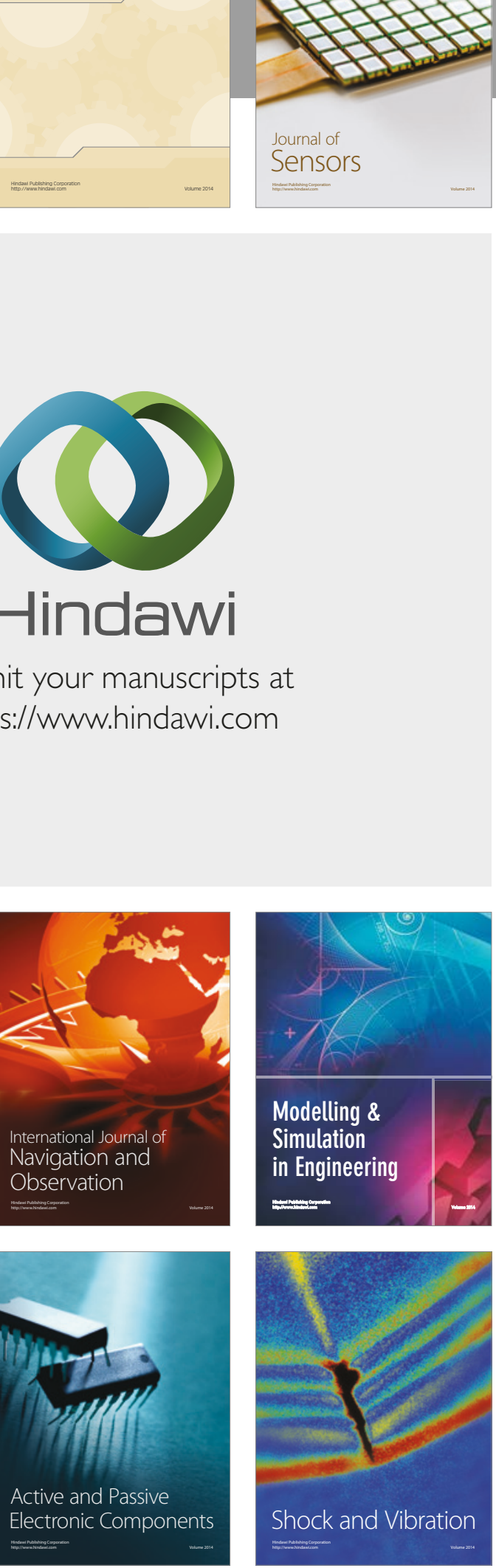
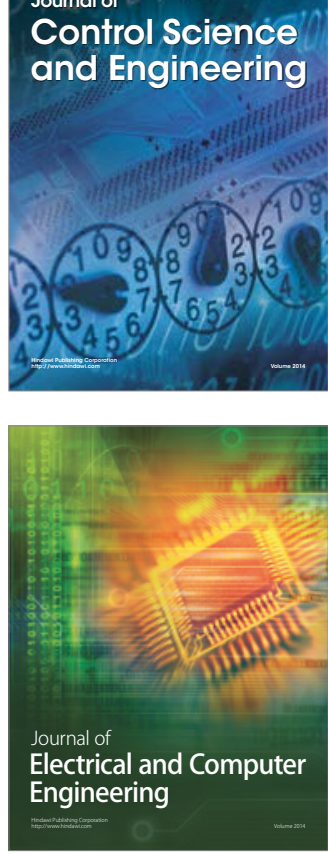

Distributed

Journal of

Control Science

and Engineering
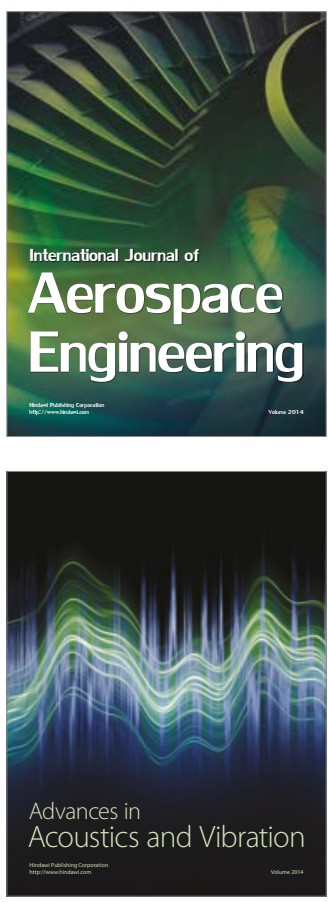

Sensor Networks 